\title{
개발정책 평가 설계
}

차 은 주 KOICA 평가실 과장

\section{목차}
I. 들어가며
II. 개발정책 평가의 기획 및 설계
III. 개발정책 평가 설계 사례
IV. 향후 개발정책 평가를 위한 시사점

\section{I. 들어가며}

개발정책(Development Policy)은 개발도상국이 자국의 발전을 위해 수립하는 정책은 물론, 공여 국 및 개발원조기관이 수립하는 원조 정책을 포함한다. 개발도상국이 수립하는 개발정책의 예로는 국가개발계획, 재정 및 경제정책, 빈곤감소전략(Poverty Reduction Strategy Papers)을 들 수 있으 며, 공여국 차원에서 수립되는 중기원조전략, 국별지원정책, 분야별·주제별 지원정책도 개발정책에 포함된다. 아울러 새천년개발목표(Millennium Development Goals, MDGs), 원조효과성을 위한 파 리선언(Paris Declaration on Aid Effectiveness)과 같이 국제적 수준에서도 개발정책이 수립되고 있다. 개발정책은 개발프로그램 및 프로제트와 같이 수립 및 운영의 목적을 갖고 있다. 따라서 체계 적이고 효과적인 정책 모니터링과 평가를 통해 목표달성도를 제고하는 것은 정책운영의 중요한 요소 라고 할 수 있다. 이 글에서는 개발정책 평가의 일반적 설계절차와 방법을 살펴보고, 아시아개발은행 (Asian Development Bank, $\mathrm{ADB}$ )의 개발정책 평가 사례를 토대로 향후 우리 개발정책 평가를 위한 시사점을 도출하고자 한다. 


\section{II. 개발정책 평가의 기획 및 설계}

개발정책의 경우 프로그램 및 프로젝트 평가에 비해 보다 시스템적인 관점을 갖고 평가범위가 넓 은 경향이 있지만, 평가절차 및 방법은 일반적인 프로그램 및 프로젝트 평가와 크게 다르지 않다. ${ }^{1)}$ 〈Box 1〉에서 보는 바와 같이 우선 예비평가를 통해 평가성(Evaluability)을 사전에 검토함으로써 평 가수행의 필요성과 적절성을 검토한다. 평가수행이 결정되면 사전조사 결과를 토대로 평가목표 및 평가범위를 확정한다. 평가의뢰인(Client)이 평가를 통해 얻고자하는 정보(Information needs)에 비 해 평가수행의 제약(시간, 자료 등)이 큰 경우가 많기 때문에 양자를 적절히 고려한 평가목표 및 평 가범위 결정이 필요하다. 평가목표가 결정되면, 목표와 정책수단(하위 프로그램, 제도 및 조직 구성 등)과의 인과관계를 구조화함으로써 평가대상을 구체화한다. 이상과 같은 사전조사 및 검토를 통해서 평가유형이 결정되며, 가장 빈번히 수행되는 정책평가 유형은 성과모니터링, 과정평가, 효과성평가, 영향평가, 효율성평가 등이다. 평가설계의 마지막 단계는 평가범위에 따라 주요평가질문(Evaluation questions)을 작성하고, 각각의 평가질문을 답하기 위한 평가기법, 조사방법, 자료분석 방법을 결정 하는 것이다.

\section{〈Box 1〉정책평가의 기획 및 설계 절차2)}

1. 예비평가 및 사전조사

2. 평가목표 및 평가범위 확정

3. 정책목표 및 수단 구조화 $\rightarrow$ 정책인과모형 작성

4. 평가유형 결정

- 성과모니터링, 과정평가, 효과성평가, 영향평가, 효율성평가 등

5. 평가설계

- 평가질문 작성

- 평가기법, 조사방법, 자료분석방법 결정

- 평가설계 검토

앞서 살펴본 내용은 정책평가의 일반적 기획 및 설계절차 라고 할 수 있다. 그러나 실제의 정책평 가에서는 다양한 제약사항이 도출되어 평가의 기획 및 설계를 제한하는데, 이것을 2011년도 KOICA 평가실이 추진 중인 “국제빈곤퇴치기여금 평가”를 사례로 살펴보도록 하겠다. 국제빈곤퇴기여금(이 하 “기여금”)은 혁신적개발재원3)의 일환으로 도입된 “항공권연대기금”의 국내 명칭으로, 국제선 항공

1) 노화준. 1983 , 정책평가론. 법문사

2) 정주택 외. 2007. 정책평가론 법문사 / 이윤식. 2010. 정책평가론 대영문화사 
권에 일정 기금을 부과해 최빈국의 질병 및 빈곤퇴치를 지원하는 제도이다. 기여금 제도는 1) 개도국 질병퇴치, 2) 빈곤 및 개발협력에 대한 국민인식 증진, 3) 새로운 개발재원 발굴에 참여하는 신흥 공 여국으로서의 한국의 국제적 인지도 증진 등 세 가지 목표를 갖고 추진되고 있다. 이러한 목표 아래, 정부는 관련 법령(국제협력단법)을 개정하고, 외교부 및 $\mathrm{KOICA}$ 에 기여금 운용 업무를 부여해 이 정 책을 집행하고 있다. 기여금은 국제의약품구매기구(UNITAID) 및 NGOs의 질병퇴치 사업을 지원하 고 있으며, 기여금 제도에 대한 인지도증진 사업이 국내외에서 추진되고 있다.

정책평가의 가장 첫 단계는 사전조사를 통해서 평가의 목표를 명확히 하는 것이다. 기여금 평가를 담당한 KOICA 평가실은 기여금 제도를 이행하고 있는 관계기관(외교부, KOICA)과의 면담을 통해 평가를 통해 얻고자 하는 명확한 정보가 무엇인지, 평가결과가 도출되면 어떻게 활용할 것인지를 확 인하였다. 외교부는 이번 평가를 통해서 기여금제도의 성과를 평가하여 그 결과를 기여금 운용심의 위원회에 제출함으로써 한시적(5년 간/2007-2012년)으로 운영되던 기여금 제도의 연장운영여부를 결정하고자 한다는 평가목표를 제시했다. 이러한 평가목적과 활용처를 고려할 때 평가범위에는 성과 평가가 포함되어야 한다. 하지만 기여금제도의 수립 당시 문서와 최근 접수된 사업운용결과보고서를 검토했을 때, 정책수준에서 측정가능한 성과목표가 부재하고, UNITAID, NGOs, KOICA 양자사업 모 두 상이한 체계와 방법으로 성과가 관리 및 평가되고 있기 때문에 일정한 기준에 따라 성과를 측정하 는 것이 쉽지 않을 것이라는 것이 파악되었다. 이외에 운용심의위원회 일정으로 인해 평가기간이 실 제로 2 개월 남짓으로 제한되어, 평가방법에 많은 제약이 따를 것이라는 점이 예상되었다. 예를 들어, 성과 모니터링 및 평가는 프로그램의 기준치와 실적치를 비교하는 방식으로 실시해야 하는데, 사업 별 자료보유 수준이 상이하였다. 성과평가가 아닌 과정평가로 초점을 바꿀 경우, 문헌조사, 관찰, 전 문가 및 담당자면접, 설문조사 등 비교적 시행가능한 방법으로 평가를 수행할 수 있으나, 성과를 보 고자 하는 기여금운용 심의위원회의 정보 수요(Information needs)를 과정평가로 충족시키기는 어 려울 것이다.

이상과 같이 의뢰인이 평가를 통해 얻고자 하는 정보와 평가를 통해 얻을 수 있는 정보간의 간극 이 생기는 경우가 많이 발생하는데 이것은 일반적으로 평가를 수행하는 과정에서 발생하는 다양한 제약(시간, 자료 등)에서 기인한 것이다. 따라서, 평가자는 평가기획 및 설계에서 이러한 제약을 사 전에 파악해 가능한 의뢰인의 정보수요에 근접할 수 있는 평가범위 및 방법을 설계해 평가를 수행해 야 한다. 다음 장에서 설명할 $\mathrm{ADB}$ 의 수자원정책 평가 또한 평가대상이 광범위한 정책평가로서 방법 론 상의 제약을 받고 있지만, 충분한 사전조사를 통해 평가범위와 평가방법을 체계적으로 설계함으 로써 상대적으로 평가결과의 유용성과 신뢰성을 확보하고 있다고 볼 수 있다.

3) 혁신적개발재원(Innovative financing for development)은 UN의 천년개발목표(MDGs) 달성을 위해 논의되는 다양한 개 발재원을 의미 (www.odakorea.go.kr 참조) 


\section{III. 개발정책평가 설계 사례}

(ADB의 수자원정책 및 관련사업 평가 / Evaluation Study of Water Policy and Related Operations, 2010)

\section{1. 평가설계 과정}

앞서 국제빈곤퇴치기여금 평가 사례에서도 보았듯이 평가의 첫 단계는 평가목표, 자료수집가능성, 제약사항 등을 고려해 “무엇을 평가할 것인지(평가범위)”와 “어떻게 평가할 것인지(평가방법)”를 결정 하는 것이다. 이번 평가의 목적은 2001년에 수립된 ADB의 수자원정책(Water Policy and Related Operations, 2001)을 평가해 향후 수자원정책 및 사업운영을 위한 제언을 도출하는 것이다. 평가팀 은 사전면담 및 $\mathrm{ADB}$ 가 기존에 보유한 자료 등을 검토한 뒤에 수자원정책을 〈표1>과 같이 3 가지 기 준으로 평가할 것을 결정했다. 우선 1) 정책과 사업이 얼마나 적절하고, 일관적인지 적절성 (Relevance)을 평가하고, 2) 정책을 어떤 방식으로 얼마나 이행되고 있는지 대응성(Responsiveness) 을 평가하며, 궁극적으로 3) 정책의 성과(Results) 즉, 투입, 산출, 결과물 달성의 효율성과 효과성을 검토하고, 장기적 영향력 확보를 위한 적절한 조치가 이루어졌는지를 평가하는 것이 계획되었다. ${ }^{4}$

〈표 1〉 $\mathrm{ADB}$ 의 수자원정책 평가기준

\begin{tabular}{l|l}
\hline \multicolumn{1}{c|}{ 평가기준 } & \multicolumn{1}{c}{ 평가범위 / 주요평가문항 } \\
\hline Relevance 적절성 & 정책과 사업은 얼마나 적절하고, 일관되었는가? \\
\hline Responsiveness 대응성 & 정책을 어떤방식으로 얼마나 이행하고 있는가? \\
\hline Results 성과 & $\begin{array}{l}\text { 지금까지의 성과는? Inputs, outputs, outcome 달성의 효율성과 효과성은? } \\
\text { 장기적 영향력을 확보하기 위한 조치는? }\end{array}$ \\
\hline
\end{tabular}

\section{2. 적절성(Relevance) 평가}

적절성(Relevance)의 경우 KOICA의 5 대 평가기준에 포함되어 있어5), 대부분의 정책 및 프로젝트 평가에 포함되는 평가기준이다. 그러나 KOICA에서 수행한 적절성 평가는 대부분 해당정책이 KOICA 의 원조전략, 수원국의 개발전략과 일치하는지를 검토해왔다. 하지만 KOICA의 원조정책은 물론 수 원국의 개발전략이 주요 개발분야를 모두 다루고 있어, 정책 및 사업이 이 개발분야를 벗어나서 수립 되거나 이행되기가 오히려 어렵기 때문에 평가를 통해 적절성 문제를 찾아보기는 힘들었다.

4) $\mathrm{ADB}$ 의 수자원정책 평가설계는 해당 평가결과보고서 및 평가계획서(Evaluation Framework)를 토대로 검토하였다. 평가결 과보고서는 $\mathrm{ADB}$ 홈페이지에서 다운로드 가능하며(mwv.adb.org) 평가계획서는 $\mathrm{ADB}$ 측에 별도 요청 후 받을 수 있다.

5) KOICA. 2008. 개발협력사업평가 가이드라인. KOICA 
$\mathrm{ADB}$ 의 수자원정책 평가의 경우 적절성 평가의 범위를 수혜자로 확장시키고 있다. 〈표2〉에서 보는 바와 같이 사업이 수원국의 국가정책뿐 아니라, 수혜지역 및 수혜자의 필요에 부합하고 있는지, 사업 이 현지의 제도적 역량에 맞게 설계되었는지를 검토한다. 평가방법은 지난 10 년간 종료 또는 이행된 사업의 종료보고서(Project completion reports, PCR), 사업성과보고서(Project performance report)에 포함된 기존의 자료를 종합하는 것으로 결정되었다. $\mathrm{ADB}$ 의 경우 지난 10 년간 종료된 수자 원 관련 사업의 숫자만 100 여 개에 이르고 있으나, 다행히 사업들이 일정한 절차 및 방법에 따라 수 혜자 필요 및 지역사회 역량에의 부합 정도를 평가하고 그 결과를 보유하고 있어 기존 자료를 활용한 종합평가가 가능했다고 볼 수 있다.

〈표 2〉수자원정책 적절성 평가질문 및 평가방법

\begin{tabular}{l|l|l}
\hline \multicolumn{1}{c|}{ 평가기준 } & \multicolumn{1}{|c}{ 평가범위 / 평가질문 } & \multicolumn{1}{c}{ 평가방법 } \\
\hline Relevance & ADB 전략, 수원국 우선순위, 국제동향 & Contextual and thematic studies \\
정책과 사업은 & 과의 일치 정도 & \\
\cline { 2 - 3 } 얼마나 일관되고 & 사업이 수원국 및 지역의 수요 및 제도 & $\begin{array}{l}\text { 기존 사업별 자료 사용 } \\
\text { 적절하였는가? }\end{array}$ \\
\cline { 2 - 3 } & 적 역량에 부합하는 정도 & Comparative studies \\
\cline { 2 - 3 } & 타 공여기관과의 조화 & PPRs) \\
\hline
\end{tabular}

아울러 적절성 평가에서는 World Bank를 비롯한 4개 개발은행의 수자원 정책과 $\mathrm{ADB}$ 의 정책을 비 교하는데 비교기준을 17 가지 개발하여 기관간 차이를 상세히 분석하고자 하였다. 〈표3〉은 평가결과 보고서에 포함된 기관간 비교표이다. 평가설계 당시에는 17 개 세부기준을 수립해 기준의 타당성에 대한 $\mathrm{ADB}$ 관계자들의 의견을 수렴하고, 실제 조사수행 전에 World Bank의 정책과 시범적으로 비교 를 실시함으로써, 비교기준 자체의 적절성을 사전에 검토하였다.

〈표 3〉타 공여기관과의 수자원정책 비교기준표

\begin{tabular}{l|l|l|l}
\hline \multicolumn{1}{c|}{ 공여기관 정책 } & ADB & World Bank & \multicolumn{1}{c}{ Beyond MDBs } \\
\hline $\begin{array}{l}\text { 대규모 수자원 사업 } \\
\text { (dams, storage) }\end{array}$ & $\begin{array}{l}\text { 신중하게 접근 중. 공공의 } \\
\text { 이익에 충분히 부합하는 } \\
\text { 지 여부가 확인 필수 }\end{array}$ & $\begin{array}{l}\text { 효과적 모델을 중심으로 } \\
\text { 다시 확대 중. 2003년 } \\
\text { 이후 67개 프로젝트, 87 } \\
\text { 억불 승인 }\end{array}$ & $\begin{array}{l}\text { 수력발전은 전세계 전력 } \\
\text { 곱급의 1/5차지. 캐나다 } \\
\text { 미국등의 경제성장 견인 }\end{array}$ \\
\hline $\begin{array}{l}\text { 수자원분배를 위한 } \\
\text { 참여적 접근 }\end{array}$ & 정책에 포함되어 있지만, \\
실행에 어려움 있음 & $\begin{array}{l}\text { 인센티브와 경제성원칙 } \\
\text { 을 정책에 반영하고 있 } \\
\text { 음. 실행에 어려움 있음 }\end{array}$ & $\begin{array}{l}\text { 칠레에 권리를 거라애원에 든 애한수사 } \\
\text { 례 있음. }\end{array}$ \\
\hline
\end{tabular}




\section{3. 대응성(Responsiveness) 평가}

대응성(Responsiveness)은 정책을 실현하기 위해 무엇을 어떻게 했는지, 하위 프로그램에 정책을 어떻게 반영했는지를 평가하는 기준이다. 앞의 적절성 평가에서와 마찬가지로 KOICA도 정책평가에 서 대응성을 일부 평가해 왔지만 표면적인 수준에서 이루어져 왔다고 볼 수 있다. 개발정책의 목표가 개발도상국의 빈곤퇴치라고 할 때, 대부분의 원조 프로그램 및 프로젝트가 궁극적으로는 빈곤퇴치를 목표로 추진되고 있기 때문에 넓은 범위에서 정책에 대응하고 있다고 평가할 수 있지만, $\mathrm{ADB}$ 사례를 보면, 대응성 평가를 위해 더욱 더욱 구체적인 평가기준을 수립할 필요가 있다는 것을 알 수 있다.

〈표 4〉 수자원정책 대응성 평가기준 및 평가방법

\begin{tabular}{|c|c|c|}
\hline 평가기준 & 평가범위 / 평가질문 & 평가방법 \\
\hline \multirow{3}{*}{$\begin{array}{l}\text { Responsiveness } \\
\text { 정책을 어떤 방식 } \\
\text { 으로 얼마나 이행 } \\
\text { 하고 있는가? }\end{array}$} & $\begin{array}{l}\text { 정책 세부이행계획 수립, 국별정책 등에 수자원정책 반영 } \\
\text { 정도 }\end{array}$ & $\begin{array}{l}\text { 내부자료 검토 } \\
\text { (Roadmaps, CPS) }\end{array}$ \\
\hline & 사업심사보고서에 정책요소 반영정도, 실제 승인된 사업비율 & 기조 사업별 자료 활용 \\
\hline & 재원확보, 직원역량강화 등 정도 & 내부자료 검토 \\
\hline
\end{tabular}

〈표4〉에서 보는 바와 같이 $\mathrm{ADB}$ 는 대응성 평가에서 1) 수자원 정책의 세부이행계획이 수립되고, 국별정책 등 여타 정책에 수자원정책이 반영되었는지, 2) 사업심사보고서에 수자원 정책요소가 반영 되고, 이러한 사업들이 실제로 얼마나 승인되었는지, 3) 정책집행을 위해 얼마나 재원을 확보하고, 직원역량을 강화했는지를 검토하고 있다. 여기에서 시사할만한 점은 수자원 정책이 여타 정책 및 하 위 사업에 “반영”된 정도를 평가하기 위해 개발한 상세 평가기준이다.

〈표5〉는 실제로 관련 사업이 수자원정책을 얼마나 반영했는지 조사하기 위해 작성한 기준표이다. 표의 가로로 2001 년 당시 수립한 수자원 정책목표 7 개중 3 개가 예시로 포함되었으며, 세로는 수자원 관련 사업요소(Component) 17 개 중 세가지를 예시로 포함하였다. 예를 들어 $\mathrm{ADB}$ 가 수행한 수자원 관련 사업이 “삼림 및 습지대 보호(Protection of forest and wetlands)" 요소를 포함하고 있다면 이 사업은 수자원 정책 중 “수자원 보급률 확대” 및 “수자원보호” 정책목표를 반영하고 있다고 평가할 수 있다. 
〈표 5〉 정책반영정도 점검표

\begin{tabular}{c|c|c|c}
\hline $\begin{array}{c}\text { 정책목표 } \\
\text { 사업요소 }\end{array}$ & $\begin{array}{c}\text { 수자원 보급률 확대 } \\
\text { (Delivery) }\end{array}$ & $\begin{array}{c}\text { 수자원 보존 } \\
\text { (Conservation) }\end{array}$ & $\begin{array}{c}\text { 수자원 거버넌스 } \\
\text { 강화(Governance) }\end{array}$ \\
\hline 산림보호 사업 & $\sqrt{ }$ & $\sqrt{ }$ & $\sqrt{ }$ \\
\hline PPP & $\sqrt{ }$ & & \\
\hline 성인지적 접근 & $\sqrt{ }$ & & \\
\hline
\end{tabular}

\section{4. 성과(Results) 평가기준 및 평가방법}

마지막 평가범위는 정책평가에서 특히 많은 제약에 부딪히게 되는 성과(Results)이다. $\mathrm{ADB}$ 의 경 우에도 성과평가의 제약요소가 발견되는데, 그것은 바로 $\mathrm{ADB}$ 의 수자원정책 목표가 지원 방향성 중 심으로 수립되어 있어서, 결과물(Outcome) 수준의 목표, 예를 들어 정책수립을 통해 수원국에 어떤 변화를 얼마나 가져오겠다는 명확한 성과목표가 부재했던 것이다. 명확한 성과목표의 수립은 성과측 정의 전제조건이다.

따라서 $\mathrm{ADB}$ 도 결국 하위 사업단위에서 성과를 종합하는 방법을 택한다. 수자원 분야 개별 프로젝 트(유상원조)는 지난 10 년간 97 건이 종료되었으며, 사업별 종료보고서에는 일정한 기준에 따라 사업 의 산출물과 결과물의 달성도, 사업의 성공적 수행여부, 사업디자인의 효율성 등이 평가되고 등급화 (Rating)되어 있었다. 개별사업의 성과관리 및 평가가 체계적으로 수행되고 있었기 때문에 적절성 평가에서와 마찬가지로 축적된 성과관련 자료를 상대적으로 쉽게 활용할 수 있었다고 볼 수 있다.

\section{〈표 6〉수자원정책 성과 평가기준 및 평가방법}

\begin{tabular}{|c|c|c|}
\hline 평가기준 & 평가범위 / 평가질문 & 평가방법 \\
\hline \multirow{4}{*}{$\begin{array}{l}\text { Results 성과, } \\
\text { 효과성, } \\
\text { 효율성 }\end{array}$} & 산출물(Output) 및 결과물(Outcomes) 달성도 & \multirow{4}{*}{$\begin{array}{l}\text { 기존 사업별 자료 활용 } \\
\text { (종료보고서 } 97 \text { 건, 기술협 } \\
\text { 력보고서 178건 등) }\end{array}$} \\
\hline & 사업의 "Success" 비율 & \\
\hline & 사업디자인이 적절성(효율성 측면) & \\
\hline & Financial and economic returns & \\
\hline
\end{tabular}




\section{IV. 향후 개발정책 평가를 위한 시사점}

$\mathrm{KOICA}$ 의 개발정책 평가에서 도출되는 제약사항 및 $\mathrm{ADB}$ 의 정책평가 사례를 통해 우리에게 주는 시사점을 짚어보고자 한다. 특히 정책의 성과를 보고자 하는 평가의뢰인과 평가의 제약 사이에서 우 리가 고려할 수 있는 대안은 무엇인지를 살펴보았다.

(1) 제약사항 1 : 정책설계의 문제 (성과목표 및 세부 정책이행계획의 부재)

정책의 성과를 평가하는 것이 어려운 일반적 이유 중 하나는 앞선 $\mathrm{ADB}$ 평가사례에서도 볼 수 있 듯이 정책수립 당시 모니터링 및 측정가능한 성과목표가 부재하고, 명확한 정책이행도구(재원 등)가 확보되지 않기 때문이다.

궁극적으로는 보다 성과중심적인 정책설계가 이루어져야겠지만, 이미 평가시점에 이른 정책의 경 우 과정평가를 강화하는 것을 대안으로 고려해 볼 수 있다. 즉, 적절성 평가를 통해 여타 개발 행위 자(Actors)와의 정책일치 및 조화를 평가하고, 특히 정책의 적절성을 수혜자 필요에의 부응 정도까 지 확장해 평가함으로써 정책의 성과를 간접적으로 점검 또는 예측할 수 있을 것이다. 또한 대응성 평가를 통해 정책의 하위 프로그램이 정책 요소들을 얼마나 반영해 시행되었는지, 정책의 이행을 위 한 효과적인 제도 및 조직이 구축되고 예산 등이 확보되었는지에 대한 면밀한 평가를 통해서도 미흡 하나마 유용한 결과 및 정보를 도출할 수 있을 것이다.

\section{(2) 제약사항 2: 기초자료(Data)의 부족 문제}

하지만 적절성 또는 대응성 평가를 강화할 경우에도 $\mathrm{ADB}$ 사례에서 보는 바와 같이 최소한 개별 프로그램 수준에서의 성과는 평가되어야 한다. 그러나 $\mathrm{KOICA}$ 를 비롯한 국내 원조기관은 개별 프로 젝트/프로그램 단위에서도 성과 모니터링 및 평가가 제대로 이뤄지지 않는 경우가 많아, 사업별 성 과자료(기준치, 실적치, 종료평가 결과 등)를 확보하는 것이 쉽지 않다.

이러한 경우에는 실제로 평가의뢰인이 만족할만한 수준의 성과측정은 어렵다고 볼 수 있다. 특히 정책목표 아래 다양한 프로그램이 광범위하게 수행되고 있을 경우에는 상대적으로 짧은 평가기간 동 안 개별사업의 성과를 재점검하기란 거의 불가능하다. 대안으로 고려해 볼 수 있는 것은 산출물 (Output) 수준의 달성도 측정을 강화하고, 대표성 있는 사업에 대한 사례조사를 보완하는 방법일 것 이다. 


\section{참고문헌}

노화준. 1983 , 정책평가론. 법문사

이윤식. 2010. 정책평가론 대영문화사

정주택 외. 2007. 정책평가론 법문사

Rossi. Peter H. 2004. Evaluation: a systemic approach. Sage 